\title{
Heart Rate Recovery from 1 Minute of Exercise in Children and Adults
}

\author{
EUGENIO BARALDI, DAN MICHAEL COOPER, STEFANIA ZANCONATO, AND \\ YAACOV ARMON \\ Division of Respiratory and Critical Care, Department of Pediatrics, Harbor-UCLA Medical Center, \\ Torrance, California, 90509
}

\begin{abstract}
Previous studies demonstrated that the time required for oxygen uptake, $\mathrm{CO}_{2}$ production, and minute ventilation to return to baseline levels after 1 -min bursts of exercise is different in children compared with adults. To test the hypothesis that the heart rate (HR) recovery time after exercise is also different in children compared with adults, we examined HR in 10 children (range 7-11 $y$ old) and 12 adults (26-42 y old) for $10 \mathrm{~min}$ after $1 \mathrm{~min}$ of cycle ergometer exercise. Each subject exercised at work rates corresponding to $\mathbf{8 0} \%$ of the lactate or anaerobic threshold (AT), $50 \%$ of the difference between AT and maximal $\mathrm{O}_{2}$ uptake $(\Delta), 100 \%$ of maximal uptake, and $125 \%$ of maximal uptake. Gas exchange was measured breath by breath. In adults, the HR recovery time increased significantly with work intensity as judged by the time constant of a single exponential curve fit to postburstexercise HR $[23 \pm 8(\mathrm{SD}) \mathrm{s}$ at $80 \% \mathrm{AT}, 55 \pm 16$ at $50 \% \Delta$ $74 \pm 13$ at $100 \%$ of maximal uptake, and $83 \pm 20$ at $125 \%$ of maximal uptakel. HR recovery time tended to increase with work intensity in children $(16 \pm 7,20 \pm 4,23 \pm 7$, and $27 \pm 9$; for $80 \% \mathrm{AT}, 50 \% \Delta, 100 \%$ of maximal uptake, and $125 \%$ of maximal uptake respectively), but to a much smaller extent, and the HR recovery time was significantly smaller in children in the high-intensity (above $A T$ ) range of exercise $(p<0.001)$. Despite the markedly faster recoveries in children, the time course of the $\mathrm{O}_{2}$ pulse $\left(\mathrm{V}_{2}\right)$ HR) was indistinguishable between children and adults. These data suggest that the regulation of HR after highintensity exercise is different in children compared with adults, and that the pulsatile delivery of $\mathrm{O}_{2}$ to the tissues is controlled during the growth period. (Pediatr Res 29: $575-579,1991)$
\end{abstract}

\section{Abbreviations}

AT, anaerobic threshold

HR, heart rate

$\dot{\mathrm{V}}_{2}, \mathrm{O}_{2}$ uptake

$\dot{\mathrm{V}}_{\mathrm{CO}_{2}}, \mathrm{CO}_{2}$ production

$\dot{\mathrm{V}}_{\mathrm{K}}$, minute ventilation

$\dot{\mathrm{V}}_{2} \max$, maximal $\mathrm{O}_{2}$ uptake

$\%$ max, \% of $\dot{\mathrm{V}}_{2} \max$

$\Delta$, difference between $\dot{\mathrm{V}}_{2} \max$ and AT

$\tau$ HR, HR recovery time

Received August 28, 1990: accepted February 5, 1991.

Correspondence and reprint requests: Dan M. Cooper M.D. A-17 Annex. Harbor-UCLA Medical Center, 1000 West Carson Street Torrance, CA 90509.

Supported in part by Grant HL1 1907. D.M.C. is the recipient of the Career Investigator Award. Amcrican Lung Association. S.Z. is a Research Fellow of the American Heart Association. Greater Los Angeles Affiliate. Y.A. is a Research Fellow of the Joseph Drown Foundation.
The adaptive response to sudden changes in metabolic rate can be characterized by physiologic responses at the beginning of exercise as well as by those occurring in the recovery phase. Sudden changes in metabolic rate are common occurrences in children who, in general, tend toward frequent short intervals of physical activity. In previous studies of gas exchange responses to exercise, we observed that growth-related changes of $\dot{\mathrm{V}}_{2}$ kinetics (i.e. the time course of $\mathrm{VO}_{2}$ adjustments at the onset of exercise) were the same in adults and children, but dynamic ventilatory $\left(\dot{\mathrm{V}}_{\mathrm{E}}\right)$ and $\dot{\mathrm{V}}_{\mathrm{CO}_{2}}$ responses were faster in children (1, 2 ). Similarly, in recent preliminary studies $(3,4)$, the recovery period (i.e. the time required to return to baseline values after 1 min of exercise) for $\dot{\mathrm{VO}}_{2}$ was surprisingly similar in adults and children over a wide range of exercise intensities, whereas recovery for $\dot{\mathrm{V}}_{\mathrm{E}}$ and $\dot{\mathrm{V}}_{\mathrm{CO}_{2}}$ was substantially faster in children compared with adults for exercise performed in the high-intensity range.

The goal of our study was to determine whether or not there were differences in the HR recovery from exercise in children compared with adults. The HR recovery from maximal exercise has been studied in children previously (5-9), and our analysis of these data indicate that younger children recover more quickly. In the earlier studies, however, duration and relative intensity of exercise were difficult to control, and direct comparisons with adults were not made. Thus, in our present investigation, the exercise duration was limited to $1 \mathrm{~min}$, the work rates were scaled to the capability of each subject, and a group of prepubertal children was compared with adults.

\section{MATERIALS AND METHODS}

Population. Ten healthy nonobese children (six boys and four girls, aged $7-11 \mathrm{y}$, mean age $9.0 \pm 1.3 \mathrm{y}$; mean weight $30 \pm 7 \mathrm{~kg}$; mean height $135 \pm 10 \mathrm{~cm})$ and 12 healthy nonobese adults (10 men and two women, aged 26-42 y, mean age $33 \pm 5$ y; mean weight $71 \pm 11 \mathrm{~kg}$; mean height $173 \pm 8 \mathrm{~cm}$ ) comprised the study population. All were volunteers, had no chronic diseases, and did not smoke or use medication. None of the adults or children were trained athletes, but it is our impression that the volunteer process results in the self selection of individuals and families with interest in sports and exercise. To minimize the confounding effect of different levels of fitness, our goal was to have the same $\dot{\mathrm{V}}_{2}$ max and AT per $\mathrm{kg}$ body weight in the adults and children. The study was approved by the Human Subjects Committee of Harbor-UCLA Medical Center. Informed consent was obtained from each subject and guardian when appropriate.

Protocol. Progressive exercise test. Each subject performed a ramp-type progressive exercise test on an upright electromagnetically braked cycle ergometer to determine the $\dot{\mathrm{V}}_{2}$ max and the AT. The AT indicates the work rate above which marked increases in blood lactate occur. These changes are accompanied by a specific pattern of gas exchange responses measured at the mouth $(10,11)$. High-intensity exercise refers to those protocols 


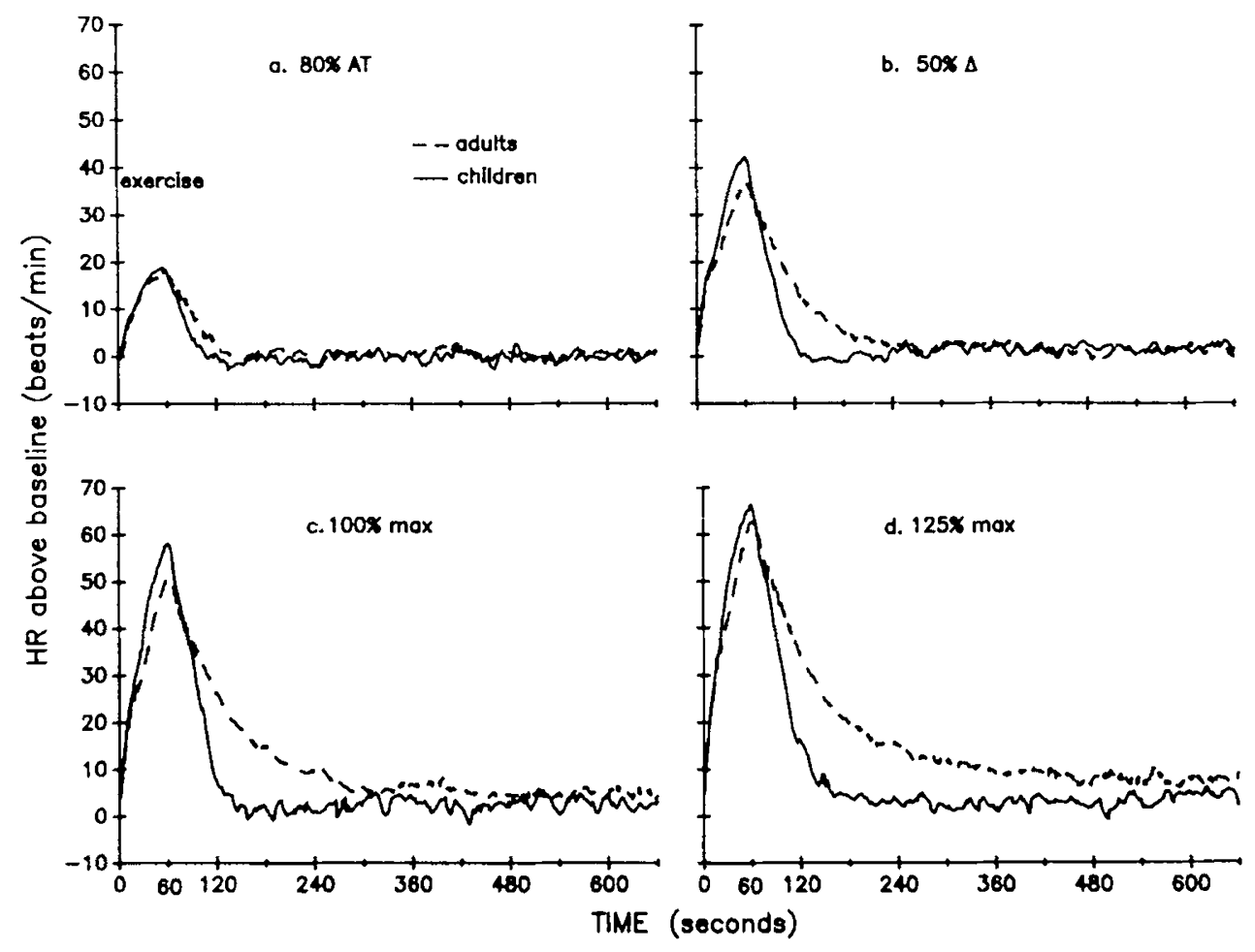

Fig. 1. Group mean HR (beats per min above baseline) in children and adults at $80 \% \mathrm{AT}$ (panel a), 50\% $($ panel $b$ ), 100\% max (panel c), and $125 \% \max ($ panel $d$ ) protocols. For all the above-AT work rates, the HR recovery was faster in children.

Table 1. Baseline, peak exercise-baseline (increment), and end-recovery $H R$ values for children and adults

\begin{tabular}{|c|c|c|c|c|}
\hline & $80 \% \mathrm{AT}$ & $50 \% \Delta$ & $100 \% \max$ & $125 \% \max$ \\
\hline \multicolumn{5}{|l|}{ Children } \\
\hline Baseline & $107 \pm 10^{*}$ & $107 \pm 10^{*}$ & $109 \pm 7^{*}$ & $108 \pm 8^{*}$ \\
\hline Increment & $18 \pm 7$ & $42 \pm 10$ & $57 \pm 8$ & $66 \pm 9$ \\
\hline End-recovery & $107 \pm 11$ & $109 \pm 9$ & $112 \pm 8 \dagger$ & $110 \pm 8 \dagger$ \\
\hline \multicolumn{5}{|l|}{ Adults } \\
\hline Baseline & $90 \pm 11$ & $94 \pm 10$ & $93 \pm 10$ & $94 \pm 8$ \\
\hline Increment & $17 \pm 5$ & $36 \pm 7$ & $50 \pm 8$ & $62 \pm 11$ \\
\hline End-recovery & $90 \pm 11$ & $95 \pm 9$ & $98 \pm 11 \$$ & $101 \pm 10 \ddagger$ \\
\hline
\end{tabular}

* Greater than baseline in adults, $p<0.001$.

$\dagger$ Greater than baseline values at comparable work intensity, $p<0.05$.

$\ddagger$ Greater than baseline values at comparable work intensity, $p<0.01$.

involving above-AT work rates and low-intensity exercise indicates below-AT work (12).

Burst-exercise test. The subjects performed 1-min bursts of varying intensity exercise: $80 \%$ of the AT, $50 \% \Delta, 100 \% \max$, and $125 \%$ max. Each subject exercised at unloading pedaling (approximately $7-12 \mathrm{~W}$ ) for 3-5 min before exercise and for $10 \mathrm{~min}$ after exercise. The tests were performed in randomized order and usually required two or three separate sessions. When studies were performed on the same day, a sufficient interval between studies was allowed so that all gas exchange parameters and HR had returned to preexercise values.

HR Measurement and Breath-by-Breath Measurements of Gas Exchange. HR was measured beat by beat by a standard lead I ECG using three electrodes placed on the chest. The values were then time interpolated (second by second) for subsequent analysis. The ECG was in continuous view via a high-persistence ECG oscilloscope.

Ventilation and gas exchange were measured breath by breath. The subjects breathed through a mouthpiece connected to a turbine flowmeter and a low-resistance, two-way valve for continuous measurement of inspired and expired volume. The apparatus dead space was $90 \mathrm{~mL} . \mathrm{CO}_{2}$ and $\mathrm{O}_{2}$ concentration were

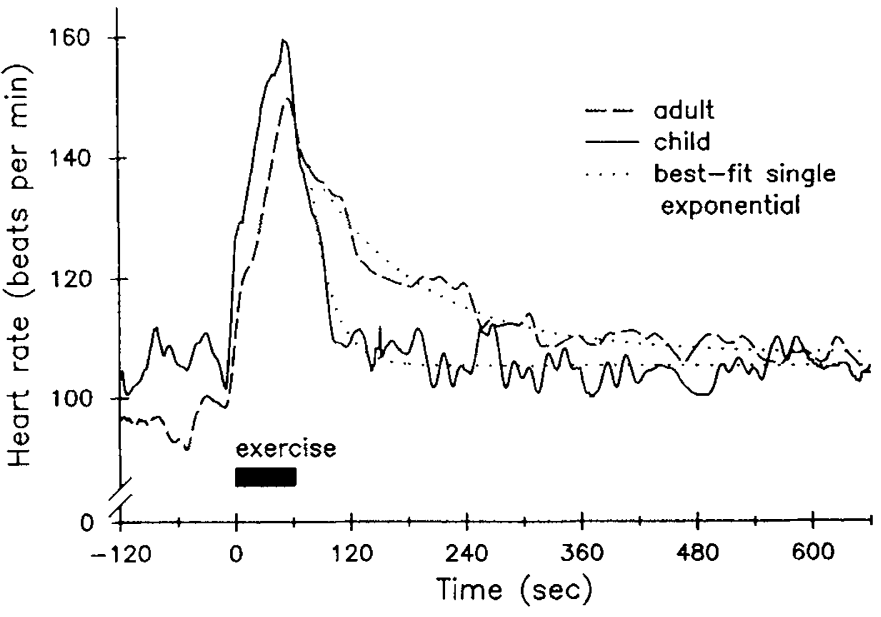

Fig. 2. Typical heart rate responses to $1 \mathrm{~min}$ of exercise at highintensity work rates (125\% of the maximal work rate) in an 8 -y-old boy and a 40 -y-old male adult. The recovery was significantly faster in the child $(\tau \mathrm{HR}=21 \mathrm{~s})$ compared with the adult $(\tau \mathrm{HR}=114 \mathrm{~s})$. The recovery data are well fitted by a single exponential model as shown by the dotted line through each data set.

measured by a mass spectrometer that sampled continually from the mouthpiece at $1 \mathrm{~mL} / \mathrm{s}$. $\dot{\mathrm{V}}_{\mathrm{E}}$ (body temperature, pressure, saturation), $\dot{\mathrm{V}}_{2}$ (stp, dry), $\dot{\mathrm{V}}_{\mathrm{CO}_{2}}$ (stp, dry), and end tidal pressure for $\mathrm{O}_{2}$ and for $\mathrm{CO}_{2}$ were computed online, breath by breath, as previously described (13).

Normalization. To compare the $\dot{\mathrm{V}}_{2} / \mathrm{HR}$ responses from the adults and children, the $\dot{\mathrm{V}}_{2}$ data were normalized to body weight. We have used body weight as a means of comparing sizedependent variables of physiologic function in previous studies, and the theoretical and experimental bases for this normalization have been outlined elsewhere (14).

Data Analysis. $\dot{V}_{2} \max$ and $A T$. $\dot{\mathrm{V}}_{2} \max$ was taken as the peak $\mathrm{VO}_{2}$ achieved by each subject before cessation of exercise. 


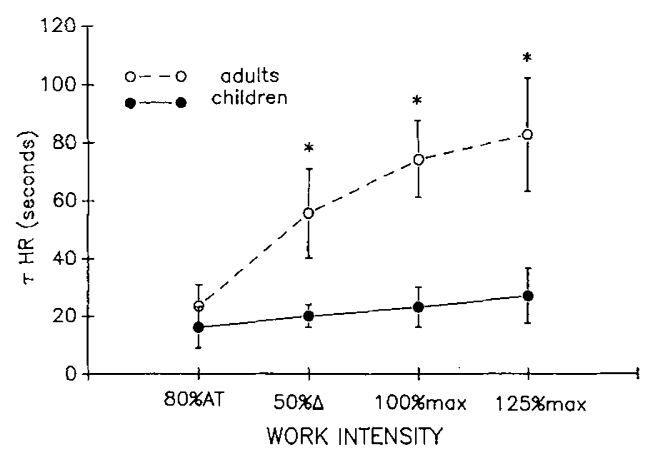

Fig. 3. $\tau$ HR constants in adults and children as a function of work intensity. Data are presented as mean $\pm \mathrm{SD}$. $\tau \mathrm{HR}$ tended to increase with work intensity in both adults and children (see text). The recovery time was significantly $\left({ }^{*}, p<0.001\right)$ shorter in children compared with adults for all the above-AT work rates $(50 \% \Delta, 100 \% \max$, and $125 \%$ max). The mean values for the increasing intensities were $16 \pm 7,20 \pm 4,23$ \pm 7 , and $27 \pm 9 \mathrm{~s}$ in children and $23 \pm 8,55 \pm 16,74 \pm 13$, and $83 \pm$ $20 \mathrm{~s}$ in adults.

The AT was measured noninvasively from the gas exchange data obtained during the progressive exercise (7-8). AT was defined as the $\dot{\mathrm{V}}_{2}$ at which the ventilatory equivalent for $\mathrm{O}_{2}\left(\dot{\mathrm{V}}_{\mathrm{E}} / \dot{\mathrm{V}}_{2}\right)$ and end tidal pressure for $\mathrm{O}_{2}$ increased without an increase in the ventilatory equivalent for $\mathrm{CO}_{2}\left(\dot{\mathrm{V}}_{\mathrm{E}} / \mathrm{V}_{\mathrm{CO}_{2}}\right)$ and end tidal pressure for $\mathrm{CO}_{2}$.

$H R$ baseline, peak, and recovery. We calculated the baseline $\mathrm{HR}$ as the mean HR in the last $30 \mathrm{~s}$ of unloaded pedaling before the onset of exercise. The peak HR was taken as the difference between the maximal HR achieved and the preexercise value. To determine whether the 10 -min period allowed for complete recovery of the $H R$, we compared the baseline $H R$ with the mean value of the last $30 \mathrm{~s}$ of the recovery phase (end-recovery).

Recovery time. $\tau \mathrm{HR}$ was determined by fitting the recovery data from each subject with a single exponential equation as previously described (15). Nonlinear techniques were used to calculate the parameters of the characteristic equation (16):

$$
\operatorname{HR}(\mathrm{t})=\mathrm{A} \cdot \mathrm{e}^{-\mathrm{kt}}+\mathrm{C}
$$

where $H R(t)$ is the value of $H R$ at time $t$ (after exercise), $A$ is a parameter, $\mathrm{k}$ is the rate constant, and $\mathrm{C}$ is the asymptotic baseline value. The time constant $(\tau=1 / \mathrm{k})$ was used to quantify the recovery time and indicates the time required to achieve $63.2 \%$ of the difference between peak and baseline values. We analyzed the time constants of $\mathrm{HR}$ at each work intensity and compared them between children and adults.

Analysis of $\dot{V} \mathrm{O}_{2}-H R$ relationship $\left(\mathrm{O}_{2}\right.$ pulse). The $\mathrm{O}_{2}$ pulse $\left(\dot{\mathrm{V}}_{2} /\right.$ $\mathrm{HR}$ ) tends to be a variable with a high noise-to-signal ratio. To improve this signal, the data for each child and adult were superimposed and averaged to yield a group-mean response in adults and children. These data were then analyzed by fitting a single exponential at each work intensity. The asymptotic SD is an estimate of the standard error of the fitted parameter (e.g. the time constant) (16).

Statistical Analysis. Analysis of variance (repeated measures) with subsequent modified $t$ test (Duncan and Bonferroni method) were used for the statistical analysis of work-intensity related differences within and between the groups of adults and children. An appropriately modified unpaired $t$ test was used to compare the HR peaks at each work rate between children and adults. Paired $t$ tests were used to compare preexercise with endrecovery HR values. Statistical significance was taken at the $p<$ 0.05 level. Data are expressed as mean \pm SD.

\section{RESULTS}

Detailed analysis of $\dot{\mathrm{V}}_{2}, \dot{\mathrm{V}}_{\mathrm{CO}_{2}}$, and $\dot{\mathrm{V}}_{\mathrm{E}}$ is the subject of parallel investigations $(3,4)$.

$\dot{\mathrm{V}} \mathrm{O}_{2} \max$ and $A T$. The $\dot{\mathrm{V}}_{2}$ max per $\mathrm{kg}$ body weight in children $\left(42 \pm 6 \mathrm{~mL} \mathrm{O} \cdot \mathrm{min}^{-1} \cdot \mathrm{kg}^{-1}\right)$ was not statistically different from that in adults $\left(41 \pm 7 \mathrm{~mL} \mathrm{O} 2 \cdot \mathrm{min}^{-1} \cdot \mathrm{kg}^{-1}\right)$. Similarly, no differences were found between the AT per $\mathrm{kg}$ in children $(25 \pm$ $\left.6 \mathrm{~mL} \mathrm{O}_{2} \cdot \mathrm{min}^{-1} \cdot \mathrm{kg}^{-1}\right)$ and adults $\left(22 \pm 3 \mathrm{~mL} \mathrm{O}_{2} \cdot \mathrm{min}^{-1} \cdot \mathrm{kg}^{-1}\right)$. These data suggest roughly similar degrees of fitness in the two groups.

Baseline, exercise, and end-recovery HR (Fig. 1, Table 1). Examples of typical HR responses at high-intensity exercise (125\% max) are shown in Figure 2. HR during unloaded pedaling was higher in children compared with adults. The exerciseinduced increase in HR (i.e. peak exercise - baseline) was the

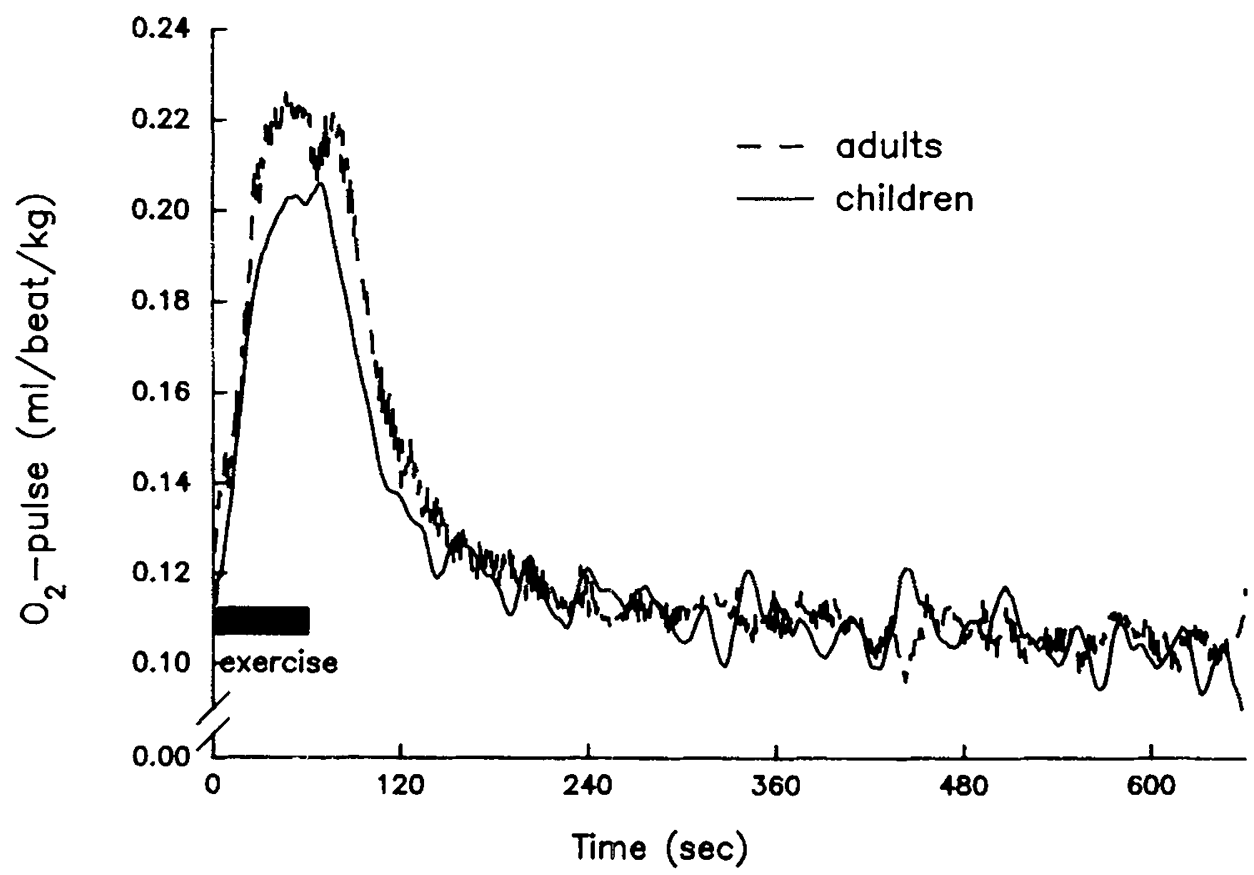

Fig. 4. $\mathrm{O}_{2}$ pulse response to $1 \mathrm{~min}$ of high-intensity exercise $(125 \% \mathrm{max})$. The data represent the group-mean response for adults and children. Note that the time course was remarkably similar in adults and children. 
Table 2. Recovery time constants for $\mathrm{O}_{2}$ pulse ( $\tau-\mathrm{O}_{2}$ pulse) in seconds*

\begin{tabular}{lcccc}
\hline & \multicolumn{4}{c}{ Work intensity } \\
\cline { 2 - 5 } & $80 \% \mathrm{AT}$ & $50 \% \Delta$ & $100 \% \max$ & $125 \% \max$ \\
\hline Children & $41 \pm 4$ & $43 \pm 2$ & $45 \pm 2$ & $49 \pm 2$ \\
Adults & $44 \pm 2$ & $41 \pm 1$ & $41 \pm 1$ & $44 \pm 1$ \\
\hline
\end{tabular}

* Data are presented as mean \pm asymptotic SD (see text).

same for adults and children at each work intensity. The endrecovery $\mathrm{HR}$ was the same as the preexercise baseline in children and adults after the $80 \% \mathrm{AT}$ and $50 \% \Delta$ protocols; however, for the higher intensity exercise, HR had not returned to preexercise values by $10 \mathrm{~min}$ of recovery. In children, end-recovery HR was $2.8 \%$ higher than baseline after $100 \%$ max and $2.6 \%$ higher after $125 \%$ max. In adults, end-recovery HR was $4.6 \%$ higher for $100 \% \max$ and $7 \%$ for $125 \%$ max.

$H R$ recovery times (Fig. 3). In adults, the $\tau \mathrm{HR}$ increased significantly throughout all the work intensities $(p<0.001)$. Although not as pronounced as for adults, $\tau \mathrm{HR}$ tended to increase with work intensity in children. Significant difference was found between $\tau \mathrm{HR}$ at $80 \% \mathrm{AT}$ and the values at both $100 \% \max$ and $125 \% \max$. Moreover, $\tau \mathrm{HR}$ at $125 \% \max$ was greater than at $50 \% \Delta$. The $\tau$ HR was substantially and significantly lower in children compared to adults $(p<0.001)$ for all the above-AT work rates $(50 \% \Delta, 100 \% \max$, and $125 \% \max )$. (We observed no differences in the $\tau \mathrm{HR}$ of females compared to males in either the adults or children; however, the sample size for comparison was small and our finding does not exclude the possible existence of gender-related differences.)

$\mathrm{O}_{2}$ pulse (Fig. 4, Table 2). The time constants of single exponential fits for the $\mathrm{O}_{2}$ pulse data were not affected by work rate. Moreover, there were no significant differences observed between adults and children. Although there were small differences in the magnitude of the $\mathrm{O}_{2}$ pulse, the time course of this response was remarkably similar in adults and children, as seen in Figure 4.

\section{DISCUSSION}

The relationship between work intensity and HR recovery was significantly different in children compared to adults. Although the recovery time was greater for high-intensity compared to low-intensity exercise in both children and adults, the magnitude of the difference in children (e.g. $\tau \mathrm{HR}$ at $125 \%$ max was $27 \pm 9$ $\mathrm{s}$ compared to $16 \pm 7 \mathrm{~s}$ at $80 \% \mathrm{AT}$ ) was substantially less than in adults (e.g. $\tau \mathrm{HR}$ at $125 \% \mathrm{max}$ was $83 \pm 20 \mathrm{~s}$ compared to $23 \pm$ $8 \mathrm{~s}$ at $80 \% \mathrm{AT}$ ). Moreover, HR recovered significantly faster in children compared to adults for each of the high-intensity exercise protocols (Fig. 1). The differences in the HR response between adults and children did not neatly reflect previously observed growth-related changes of the response dynamics of either $\dot{\mathrm{V}}_{\mathrm{E}}$ or $\dot{\mathrm{V}}_{2}$; rather, the changes in $\mathrm{HR}$ dynamics seem to reveal regulatory mechanisms associated with both metabolic rate per se and neuroendocrine modulation of physiologic function.

Previous work (done in adults) demonstrated that HR during dynamic exercise is regulated by a combination of neural, hormonal, and intrinsic mechanisms $(15,17)$. Immediately after exercise, accelerating influences from higher brain centers and peripheral nerve reflexes diminish, and $H R$ is thought to be primarily regulated by restoration of vagal inhibitory tone and by prevailing levels of circulating catecholamines $(15,18)$. The role of neural control of HR response was also recently demonstrated in exercise studies of patients who had undergone heart transplants $(19,20)$ an in vivo model of a virtually denervated heart. In these individuals, treadmill exercise revealed a drastically slowed HR increase at the onset of exercise (HR increased only after the first $60-90 \mathrm{~s}$ ) as well as a slowed decrease at the end of exercise (HR did not begin to slow for 1-2 min after exercise stopped). Moreover, there was a strong correlation be- tween the HR response in these patients and plasma catecholamines, reflecting the strong correlation recently found between changes in blood norepinephrine levels and HR response to exercise in healthy subjects (21). These observations indicate that sympathetic-parasympathetic factors are responsible for the rapid $\mathrm{HR}$ responses and circulating catecholamines modulate $\mathrm{HR}$ responses more slowly.

The largest differences in $\tau$ HR between adults and children occurred after high-intensity exercise, and it is in the above-AT range where increases in hydrogen ion, lactate, and catecholamines are known to be smaller in children compared with adults (22-24). Thus, we hypothesize that the differences in HR response to work intensity are a reflection of substantially different hormonal and metabolic responses to high-intensity exercise in adults compared with children. The mechanisms of the different lactate, catecholamine, and hydrogen ion responses to highintensity exercise have not been fully elucidated, nor are there data that specifically address the clearance of lactate, hydrogen ion, and catecholamines after exercise in children compared with adults.

There may be other factors contributing to the differences in recovery HR kinetics between adults and children. The $\dot{\mathrm{V}}_{2} \mathrm{max}$ and $\mathrm{AT}$ per $\mathrm{kg}$ were the same in adults and children, which suggests a similar level of aerobic "fitness." But the speed of cardiorespiratory adjustment at the onset of and in recovery from exercise have also been suggested as indicators of fitness, and measurements of dynamic responses like $\tau \mathrm{HR}$ may represent different adaptive mechanisms than do the $\dot{\mathrm{V}}_{2} \max$ or the AT (25). And although neither the adults nor the children studied were trained athletes, different levels or types of habitual activity could exist in these two populations. In addition, peripheral chemoreceptor contribution to ventilation during exercise is somewhat different in children compared with adults (26), and the carotid bodies are known to have cardiac as well as respiratory effects $(27,28)$. The peripheral chemoreceptors are stimulated by $\mathrm{CO}_{2}$, and differences in body composition, circulation time, and $\mathrm{CO}_{2}$ carriage in the blood could affect the transport of $\mathrm{CO}_{2}$ produced in the cells during exercise to the carotid bodies.

The results of an earlier investigation of the relationship between body size, $\dot{\mathrm{V}}_{2}$, and HR during low-intensity exercise (29) prompted us to speculate that ".... the dynamic relationship between $\dot{\mathrm{V}}_{2}, \mathrm{HR}$, and body weight is constant during growth [and] identifies a set of 'regulated' parameters of cardiorespiratory function." We wondered if this speculation held for the special case of high-intensity exercise. To examine this, we analyzed the $\mathrm{O}_{2}$ pulse data from the present subjects. The $\mathrm{O}_{2}$ pulse is the amount of oxygen extracted per heart beat and is determined by the stroke volume and the arteriovenous $\mathrm{O}_{2}$ content difference (29). When normalized to body weight, the $\mathrm{O}_{2}$ pulse per $\mathrm{kg}$ indicates the pulsatile delivery of oxygen scaled to body size. As can be seen in Figure 4 and in Table 2, the temporal response of the $\mathrm{O}_{2}$ pulse was remarkably constant between adults and children and among the various work rates. This similarity was evident even though the recovery time courses of the individual components (i.e. $\mathrm{HR}$ and $\mathrm{VO}_{2}$ ) were quite different. The size of the $\mathrm{O}_{2}$ pulse during recovery is determined by the time constants of the individual responses as well as their magnitude, and it was this particular combination (magnitude and recovery $\tau$ of $\dot{\mathrm{V}}_{2}$ and $\mathrm{HR}$ ) that was adjusted during exercise, resulting in the remarkable stability of the $\mathrm{O}_{2}$ pulse response. It appears that the link between metabolic demand and cardiorespiratory response during growth can be characterized by tight control of the $\dot{\mathrm{V}}_{2}$ pulse per $\mathrm{kg}$ of body mass. How disease of the heart, lungs, or tissues affects this regulation or the dynamics of HR recovery during exercise is not yet known.

\section{REFERENCES}

1. Cooper DM, Berry C, Lamarra N, Wasserman K 1985 Kinetics of oxygen uptake and heart rate at onset of excrcise in children. J Appl Physiol 59:211 217 
2. Cooper DM, Kaplan M, Baumgarten L, Weiler-Ravell D, Whipp BJ, Wasserman $\mathrm{K} 1987$ Coupling of ventilation and $\mathrm{CO}_{2}$ production during exercise in children. Pediatr Res 21:568--572

3. Zanconato S, Armon Y, Barstow TJ, Cooper DM 1989 Gas exchange response to burst of exercise in children and adults. Am Rev Respir Dis 139:A88(abstr)

4. Armon Y, Zanconato S, Barstow TJ, Cooper DM 1989 Ventilatory response to bursts of exercise in children and adults. Pediatr Res 25:363A(abstr)

5. Cumming GR, Everatt D, Hastman L 1978 Bruce treadmill test in children: normal values in a clinic population. Am J Cardiol 41:69-75

6. Pels AE, Gilliam TB, Freedson PS, Geenen DL, Macconnie SE 1981 Heart rate response to bicycle ergometer exercise in children ages 6-7 years. Med Sci Sports Exerc 13:299-302

7. Riopel DA, Taylor AB, Hohn AR 1979 Blood pressure, heart rate, pressurerate product and electrocardiographic changes in healthy children during treadmill exercise. Am J Cardiol 44:697-704

8. Wanne OPS, Haapoja E 1988 Blood pressure during exercise in healthy children. Eur J Appl Physiol 58:62-67

9. Washington RL, van Gundy JC, Cohen C, Sondheimer HM, Wolfe RR 1988 Normal aerobic and anaerobic exercise data for North American school-age children. J Pediatr 1 12:223-233

10. Wasserman K, Whipp BJ, Koyal SN, Beaver WL 1973 Anaerobic threshold and respiratory gas exchange during exercise. J Appl Physiol 35:236-243

11. Cooper DM, Weiler-Ravell D, Whipp BJ, Wasserman K 1984 Aerobic parameters of exercise as a function of body size during growth in children. $J$ Appl Physiol 56:628-634

12. Cooper DM, Barstow TJ, Bergner AJ, Lee W-NP 1989 Blood glucose turnover during high- and low-intensity exercise. Am J Physiol 257:405-412

13. Beaver WL, Lamarra N, Wasserman K 1981 Breath-by-breath measurement of true alveolar gas exchange. J Appl Physiol 51:1662-1675

14. Cooper DM 1989 Development of the oxygen transport system in normal children. In: Bar-Or O (ed) Advances in Pediatric Sport Sciences, Vol. 3 Biological Issues. Human Kinetics Books, Champaign, IL, pp 67-100

15. Savin W, Davidson D, Haskell WL 1982 Autonomic contribution to heart rate recovery from exercise in humans. J Appl Physiol 53:1572-1575

16. Jennrich R 1988 Nonlinear regression. In: Dixon WJ (ed) BMDP Statistical Software Manual. University of California Press, Berkeley, pp 857-884
17. Darr KC, Basset DR, Morgan BJ, Thomas DP 1988 Effects of age and training status on heart rate recovery after peak exercise. Am J Physiol 254:H340H343

18. Blomqvist CG, Saltin B 1983 Cardiovascular adaptations to physical training. Annu Rev Physiol 45:169-189

19. Cerretelli P, Grassi B, Colombini A, Caru B, Marconi C 1988 Gas exchange and metabolic transients in heart transplant recipients. Respir Physiol 74:355-371

20. Degre SG, Niset GL, De Smet JM, Ibrahim T, Stoupel E, Le Clerc JL, Primo G 1987 Cardiorespiratory response to early exercise testing after orthotopic cardiac transplantation. Am I Cardiol 60:926-928

21. Perini R, Orizio C, Comande A, Castellano M, Beschi M, Veicsteinas A 1989 Plasma norepinephrine and heart rate dynamics during recovery from submaximal exercise in man. Eur $J$ Appl Physiol 58:879-883

22. Matejkova J, Kiprivova Z, Placheta Z 1980 Changes in acid-base balance after maximal exercise. In: Placheta $Z$ (ed) Youth and Physical Activity. JE Purkyne University, Brno, pp 191-199

23. Eriksson BO 1980 Muscle metabolism in children-a review. Acta Paediat Scand 283:20-28

24. Lehmann M, Keul J, Korsten-Reck U 1981 The influence of graduated treadmill exercise on plasma catecholamines, aerobic and anaerobic capacity in boys and adults. Eur J Appl Physiol 47:301-311

25. Hagberg JM, Hickson RC, Ehsani AA, Holloszy JO 1980 Faster adjustment to and recovery from submaximal cxercise in the trained state. J Appl Physiol $48: 218-224$

26. Springer C, Cooper DM, Wasserman K 1988 Evidence that maturation of the peripheral chemoreceptors is not complete in childhood. Respir Physiol $74: 55-64$

27. Honda Y, Hashizume I, Kimura H, Severinghaus JW 1988 Bilateral carotid body resection in man enhances hypoxic tachycardia. Jpn J Physiol 38:917928

28. Gupta PD, Singh M 1987 Tachycardia of carotid chemoreceptors originates in apneic asphyxia in dogs. Am J Physiol 253:H591-H597

29. Cooper DM, Weiler-Ravell D, Whipp BJ, Wasserman K 1984 Growth-related changes in oxygen uptake and heart rate during progressive exercise in children. Pediatr Res 18:845-85 